\title{
THE EFFECT OF DISEASE AND INJURY ON THE ADRENAL CORTEX OF STILLBORN AND NEWBORN INFANTS
}

\author{
BY \\ F. A. LANGLEY and J. C. BURNE \\ From the Departments of Obstetrics and Gynaecology and of Pathology, University of Manchester
}

(RECEIVED FOR PUBLICATION NOVEMBER 4, 1954)

The activity of the adrenal cortex in the newborn has usually been studied biochemically or by the response to stimuli which are adequate in the adult (Bongiovanni, 1951; Heller, 1954). Such investigations have been made on normal, healthy infants. The effect of systemic disease on the adrenal cortex of children, from birth to 15 years, has been studied morphologically by Stoner, Whiteley and Emery (1953). Changes in the adrenal cortex of the foetus and newborn infant may be (a) specific, i.e., peculiar to the disease or injury suffered by the infant, such as the occurrence of haemopoietic foci in the adrenals in haemolytic disease, or (b) non-specific, i.e., not peculiar to the disease or injury suffered by the infant. The non-specific response is usually recognized by variations in the lipid content of the adult (definitive) zone of the cortex.

This paper records an investigation into the nonspecific response to disease and injury of the definitive zone of the adrenal cortex in stillborn foetuses and infants dying during the first week of life.

\section{Material and Methods}

The material for the study of the non-specific response of the adrenal cortex consisted of a sample of 158 cases drawn from a pool of about 1,900 necropsies performed on stillborn foetuses and newborn infants. The sample was unselected except that macerated foetuses were excluded and none surviving seven days or more was included. The sections of the glands were stained routinely by haematoxylin and eosin and, for lipid, by Sudan IV and haemalum.

Assessment of Changes in Lipid Content of Adult Cortex. Although in adrenals of this age the definitive cortex cannot be divided into the three classical zones, yet there is an ill-defined architectural difference between the sub-capsular region and that adjacent to the foetal cortex. This difference is reflected in the lipid content of the definitive cortex, the outer (sub-capsular) third usually containing less lipid than the inner two-thirds during the first week of life. In the first place the lipid content of the two parts was assessed separately. It was then found that the changes in the outer third ran closely parallel to the changes in the inner two-thirds and thus the state of the definitive cortex could be assessed as a whole.

For the sake of brevity and clarity, and without prejudice to any other meaning, the following terminology was adopted. The cortex was considered to be 'resting' if it contained abundant sudanophilic droplets (Fig. 1),

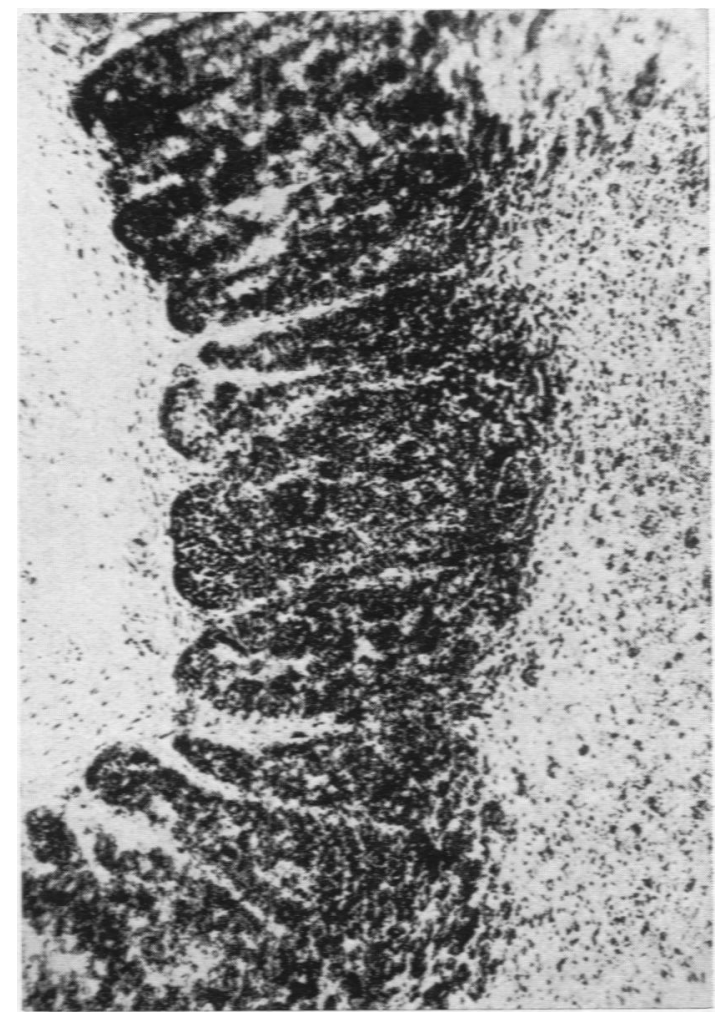

Frg. 1.-Resting adrenal cortex. The definitive cortex is packed with lipid. From a full-term female infant, aged 1 day, dying from congenital morbus cordis. Sudan IV and haemalum; $\times 90$. 
which in the inner two-thirds were large; to be 'active' when the number and size of the droplets had diminished (Fig. 2); and 'exhausted' when there was complete loss of sudanophilia in the definitive cortex. When the diminution in sudanophilia was slight it was frequently patchy.

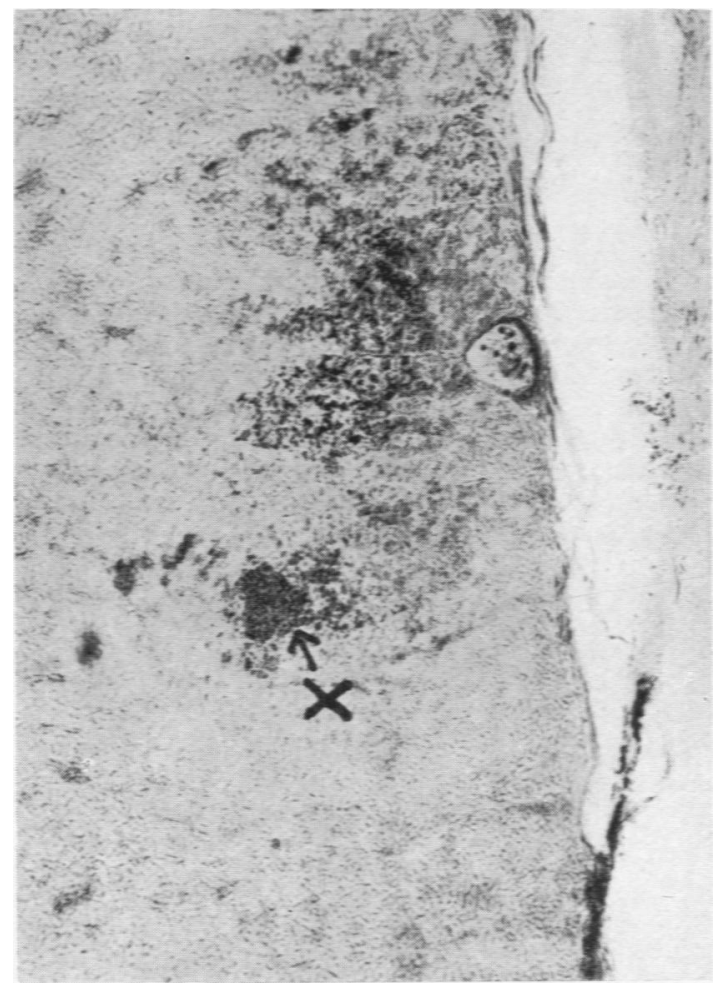

Fig. 2.-Active adrenal cortex. In the definitive cortex there is a general diminution of sudanophilia, more obvious in the subcapsular zone. The distribution is patchy. A haemopoietic focus can be seen (X). From a full-term male infant, aged 36 hours, dying from haemolytic disease. Sudan IV and haemalum; $\times 90$.

\section{Results}

Variation in Sudanophilia with Age. The changes in lipid content of the adult cortex with age are shown in Fig. 3. The proportion of stillborn infants with resting adrenals was just under half ( 28 out of 64 ) and diminished to a minimum in those dying between 12 and 24 hours, after which it rose to about the level in the stillborn group. This fall in the frequency of resting glands was not statistically significant, as tested by a $2 \times 2$ contingency table, but it suggested that further analysis might be interesting.

In this figure and in those that follow the area of each circle represents the number of cases in the corresponding sub-group and the areas of the sectors the number of cases in which the adrenals are resting, active or exhausted, respectively. Apart from Fig. 3, the active and exhausted adrenals are grouped together as 'diminished' sudanophilia.

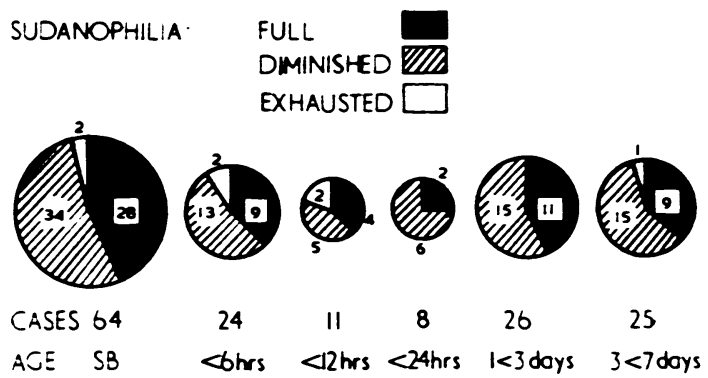

Fig. 3.-The relation between the sudanophilia of the definitive cortex and the age at death in 158 infants.

Asphyxia. The upper part of Fig. 4 shows that among asphyxiated infants there was no change in frequency of resting glands in infants who survived compared with those who were stillborn. The term 'pure' asphyxia is used to indicate that in these infants neither injury, infection nor other disease was found at the post-mortem examination. In none of these 33 cases was there evidence of focal necrosis or arteriolar changes in the adrenal.

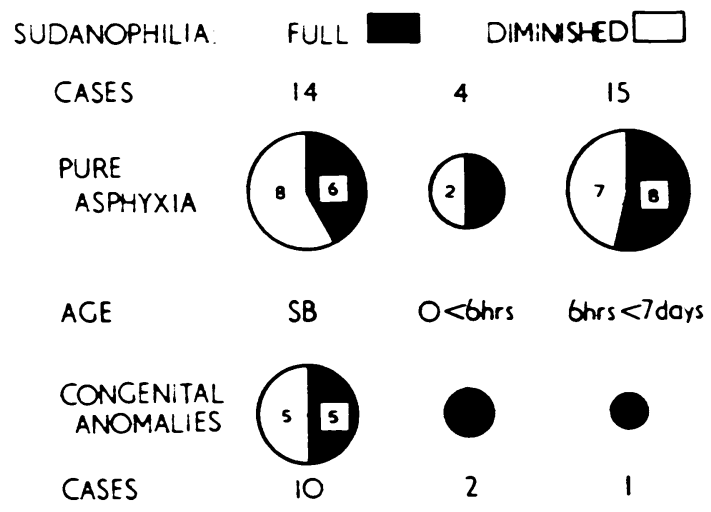

FKG. 4.-The effect of 'pure' asphyxia and congenital anomalies on the lipid content (sudanophilia) of the definitive cortex.

Congenital Anomaly. The lower part of Fig. 4 shows that in stillborn infants the frequency of resting glands was not significantly different in those dying of congenital anomalies from that in those dying of asphyxia and of injury; there was no evidence that survival reduced this frequency. This group of congenital anomalies was small because of the exclusion of those dying with any other detectable lesion. 
Birth Injury. The effect of birth injury was examined both in respect of cases of 'pure' birth injury, i.e., infants dying with no complication, and also those in whom the injury was combined with asphyxia. These two groups gave essentially the same result; because of this and because asphyxia, by itself, had no effect on the incidence of resting glands, the results have been combined in Fig. 5 .

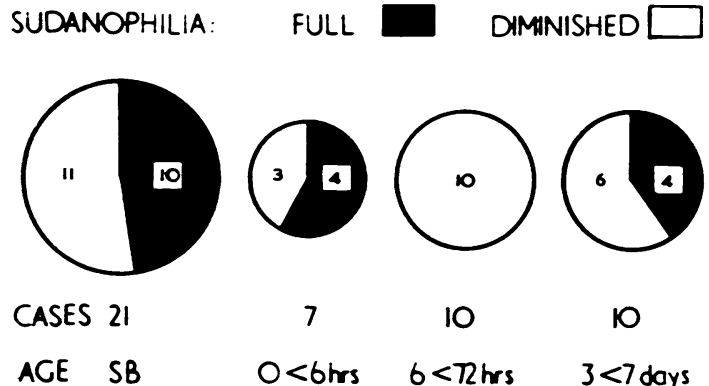

Fig. 5.-The effect of birth injury on the lipid content (sudanophilia) of the definitive cortex.

Both in stillborn infants and in infants dying within six hours of birth the frequency of resting adrenals was essentially the same as in the groups of 'pure' asphyxia and congenital anomalies. None of the infants dying between six and 72 hours after birth had resting glands, all showed diminution of adrenal cortical sudanophilia and two were exhausted. These differences are statistically significant (see Table 1). After three days four of 10 infants had resting glands.

TABLE 1

THE EFFECT OF BIRTH INJURY

\begin{tabular}{|c|c|c|c|}
\hline $\begin{array}{c}\text { State of } \\
\text { Definitive Cortex }\end{array}$ & $\begin{array}{l}\text { Stillborn or } \\
\text { Surviving Less } \\
\text { than } 6 \text { Hours }\end{array}$ & $\begin{array}{l}\text { Dying between } \\
6 \text { and } 72 \text { Hours }\end{array}$ & Total \\
\hline Resting & 14 & 0 & 14 \\
\hline Active or exhausted & 14 & 10 & 24 \\
\hline Total & 28 & 10 & 38 \\
\hline
\end{tabular}

Whence $P$ is less than 0.005. This indicates that when infants die from birth injury active or exhausted glands are significantly more common in infants dying between six and 72 hours than in stillborn infants and those surviving less than six hours.

It should be emphasized that this was an unselected sample drawn from a much larger population. Another sample would be expected to have the same general pattern but to differ in detail. For example, infants are occasionally found dying between six and 72 hours after birth in whom the definitive adrenal cortex is in the resting condition, but such cases are infrequent and do not invalidate these findings.

Haemolytic Disease. Eighteen infants out of the sample of 158 suffered from haemolytic disease (Fig. 6). Of those who were stillborn or died

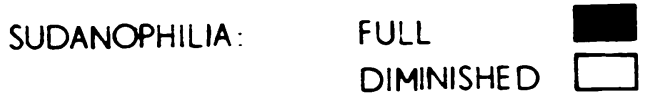

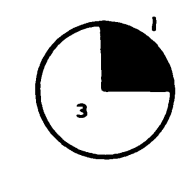

CASES 4

ACE SB

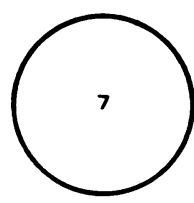

7

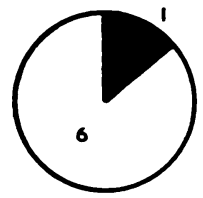

7
FIG. 6.-The effect of haemolytic disease on the lipid content (sudanophilia) of the definitive cortex.

within six hours, only one out of 11 had adrenals in a resting state. Compared with the effects of asphyxia, congenital anomaly and birth injury this is statistically significant (Table 2). Likewise there

TABLE 2

COMPARISON OF HAEMOLYTIC DISEASE WITH OTHER CAUSES OF DEATH IN STILLBORN INFANTS AND INFANTS SURVIVING LESS THAN SIX HOURS

\begin{tabular}{ccccccc}
\hline $\begin{array}{c}\text { State of } \\
\text { Adult Cortex }\end{array}$ & & $\begin{array}{c}\text { Other } \\
\text { Causes }\end{array}$ & & $\begin{array}{c}\text { Haemolytic } \\
\text { Disease }\end{array}$ & Total \\
\hline Resting & $\ldots$ & $\ldots$ & 29 & & 1 & 30 \\
Active or exhausted &. & 29 & & 10 & 39 \\
\hline Total & $\ldots$ & $\ldots$ & 58 & 11 & 69
\end{tabular}

Whence $P$ is 0.0113 . This indicates that when infants die from haemolytic disease active or exhausted glands are significantly more common than in infants dying from other causes at this age.

was a marked difference between those dying of haemolytic disease between six hours and seven days and those dying of asphyxia and congenital anomaly.

Pneumonia. Pneumonia was present in 11 infants and was usually associated with a complicating lesion such as asphyxia or birth injury. This group is too small for a detailed analysis. Of the five infants who were stillborn or who died within six hours of birth, three showed some loss of sudanophilia in the definitive cortex and one complete loss. This pattern is similar to that found in haemolytic disease. Of those who survived more than six hours, only three out of six showed diminution of sudanophilia. 
Weight of the Adrenal in Rehation to Lipid Content. Selye (1936a, 1936b) showed that in the mature rat the adrenal responds to noxious stimuli in the phase of the 'alarm' reaction by loss of lipid and increase in weight. In Fig. 7 the straight line is the regression adrenals of premature infants as in those born at full term.

Discussion

Infants who suffered birth injury showed diminution of lipid in the definitive cortex six to 72 hours

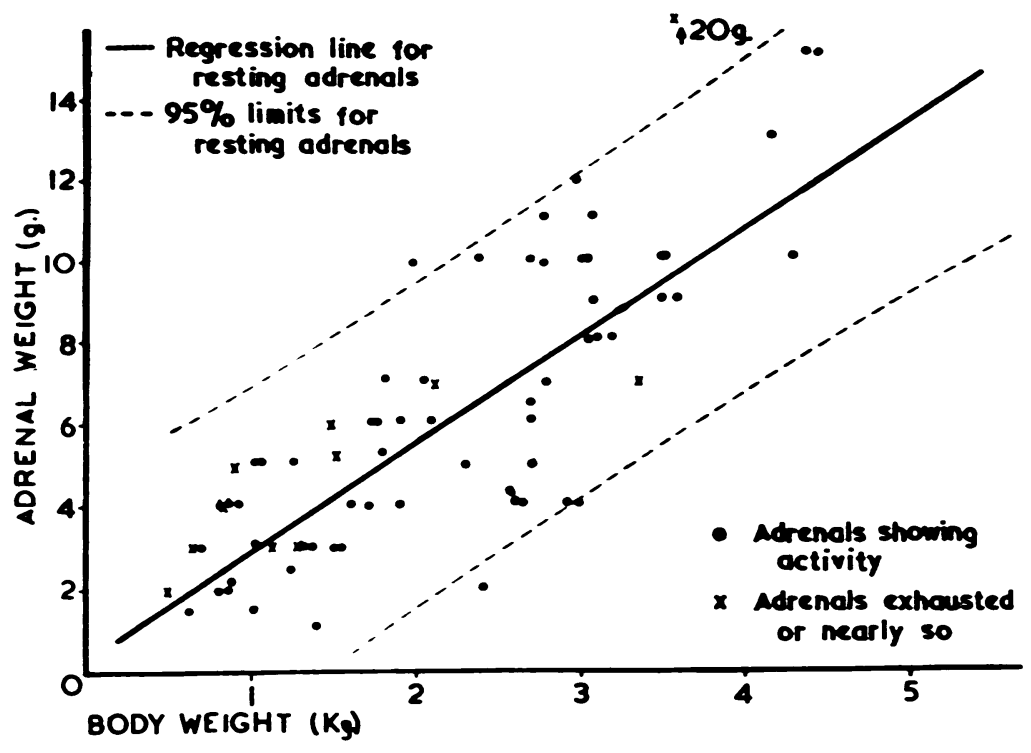

Fig. 7.-The relation between adrenal weight (both glands together) and body weight. after birth; the loss of lipid occurred less frequently in those who survived more than three days. Two interpretations of this are possible. First, that between six and 72 hours the adrenal response to injury reaches a maximum to be followed by a recovery phase, or secondly, that adrenal failure plays a part in causing death in the first three days of life. Since this is not an animal experiment there is no way of deciding between these two possibilities. The pattern is clearly similar to that in adult rats exposed to noxious agents (Selye, 1936a; 1936b) in which, after a latent period of six hours, an 'alarm' reaction occurs which lasts up to $\mathbf{4 8}$

line of adrenal weight on body weight for those infants in whom the adrenals were in the resting state. The curved, interrupted lines indicate the limits within which $95 \%$ of the resting adrenals lie. When the weights of the adrenals showing diminution in lipid are superimposed on this framework there is no evidence of increase in weight with loss of lipid from the adult cortex; most of the points lying within the $95 \%$ range and being symmetrically distributed about the regression line. Cases of haemolytic disease have been excluded from this analysis because the adrenal is affected by changes specific to that disease such as oedema (Burne and Langley, 1955).

Prematurity. In the preceding analysis no consideration has been given to the effects of prematurity, full-term and premature infants being grouped together. The adult cortex of live-born infants showed less sudanophilia in premature than in full-term infants (Fig. 8). This difference (which is not statistically significant) might be attributed to lack of development of sudanophilic granules in premature adrenals. This was not so, since in stillborn infants full sudanophilia was as frequent in the hours and is characterized by loss of adrenal cortical lipid and by adrenal hypertrophy. Adrenal hypertrophy was not detected in this series (see Fig. 7) either because it did not occur or because of the relatively large size of the foetal zone masking changes in the adult zone.

Haemolytic disease of the foetus and newborn, in contrast to birth injury, is a chronic disease which starts to affect the infant before birth and the response of the adrenal differs. Both in the stillborn group and in infants who survived up to six days there was, as a group, diminished cortical lipid. This corresponds to Selye's third stage of the stress syndrome which occurs when the noxious stimulus is slight and prolonged. Stoner et al. (1953) found little response to haemolytic disease, five out of six cases in their series being in the resting phase. The adrenal response to pneumonia in stillborn infants and in infants surviving less than six hours was similar to that in haemolytic disease. Perhaps this is because infection may precede delivery by some hours, e.g., when the membranes have been ruptured 48 hours, or owing to the cumulative effects of the multiple lesions which are usually present. 
Although the adrenal response of neonatal infants resembles the stress reaction described by Selye in adult rats there are a number of differences. The response to stress in rats affects the fasciculate zone (Greep and Deane, 1949). In the alarm reaction this zone suffers lipid depletion and enlargement. In the newborn infant there is no recognizable zona fasciculata; the lipid depletion affects the whole width of the definitive cortex and no enlargement can be recognized by increase of weight or thickness. In the adrenals of rats an increase in sudanophilia occurs in the 'resistance' phase with a marked increase in birefringence, which is maintained after the secondary fall in sudanophilia begins. This present study of neonatal adrenals is based on material obtained at routine post-mortem examinations over a period of years and no refined histochemical tests have been used. Thus it has not been possible to distinguish between a resting gland and one in the resistance phase, and glands showing full sudanophilia in infants dying from four to six days after birth may be in the phase of 'resistance'. Since the functional roles of the zones in the human adrenal are not necessarily the same as in the rats (Bergner and Deane, 1948), and since we are considering the response of an immature adrenal, the comparison between the adult rat and the infant must not be pressed too far.

The infant adrenal appears to show no response to asphyxia in terms of changes in sudanophilia of the definitive cortex. Gruenwald (1951) described other changes in the adrenal, namely, focal necrosis and haemorrhage. We have seen such necrosis of the adrenals but not in this series and not associated with uncomplicated asphyxia. Thus two cases were of haemolytic disease dying at $20 \mathrm{~min}$. and four days respectively, and another in which there was a clinical history of asphyxia in a stillborn infant, but no evidence of such at necropsy. It may well be that necrosis is a response to chronic stress, as described by Selye and Stone (1950), rather than to asphyxia. Haemorrhage occurs in many parts of the body in asphyxia and there is nothing especially odd in its occurring in the adrenal. It is probable that the foetus is adapted metabolically to anoxia, by use of anaerobic mechanisms (Wilson, Reardon and Murayama, 1948), and thus asphyxia is not an adequate stimulus to set going the stress reaction.

Wolman (1952) showed that the eosinophil response to A.C.T.H. was the same in premature as in full-term infants. Jailer, Wong and Engle (1951) tested adrenal function by the effect of injected adrenalin on the eosinophil count and found that there was less fall in the count the more premature the infant. Since response of the adrenal cortex to adrenalin is mediated through the pituitary, whilst that to A.C.T.H. is a direct response of the adrenal it may be supposed that the observations of Jailer et al. reveals immaturity of the pituitary-adrenal axis in premature infants. If the reaction of the adrenal to birth injury and haemolytic disease is a stress reaction in Selye's sense then it is mediated by the pituitary-adrenal axis. Using the yardstick of diminished cortical lipid we have failed to demonstrate immaturity of this mechanism.

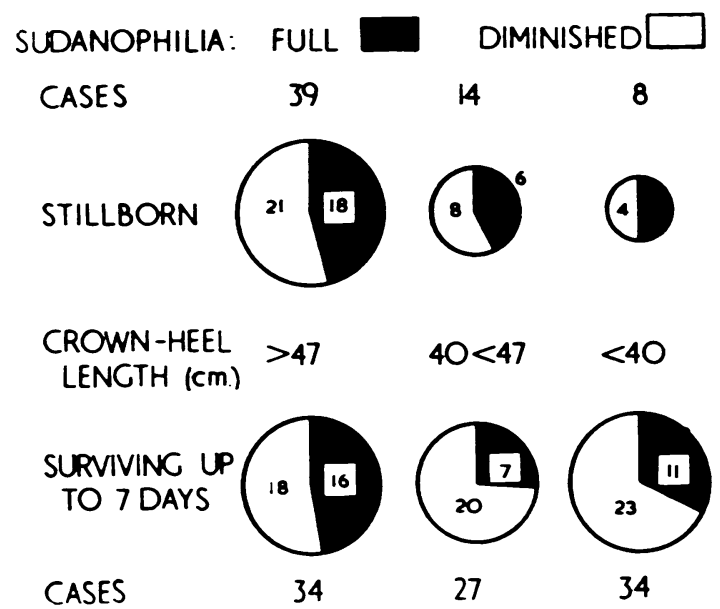

Fig. 8. - The effect of prematurity on the lipid content (sudanophilia) of the definitive cortex.

The results of Stoner et al. (1953) differ from ours in a number of ways, probably because their method of assessment of the morphological changes is different. They write, 'At birth the [lipid] droplets are fairly uniformly distributed between the surface and the junction of the adult [definitive] cortex with the X-zone. A few days after birth they tend to become concentrated in the inner half of the adult cortex', and quote Sarason (1943) in support of this description. In our observations this appearance is well recognized, but is associated with a general fall in sudanophilia and is considered to represent adrenal activity; Stoner et al. finding it in their control series consider it 'normal'. Their controls are described as instances of sudden death, 'stillbirth, asphyxia, road accident, etc.'. It seems unlikely that more than a few of their 23 control infants died in the first week as a result of road accidents or that stillbirth or asphyxia can be considered normal. We have taken the view that no infants dying under seven days can be used as normal controls; the changes in adrenal morphology can best be assessed by comparing groups of infants in 
relation to the disease or injury causing death and the duration of survival.

\section{Summary}

The definitive adrenal cortex of stillborn and newborn infants showed no response to asphyxia. Birth injury caused a diminution of cortical lipid six to $\mathbf{7 2}$ hours after birth; the diminution occurred less frequently in those who survived more than three days. Haemolytic disease, in contrast to birth injury, is a chronic disease starting before birth, and the response differed; both in the stillborn group and in infants who survived up to six days there was diminished cortical lipid. Neonatal pneumonia, beginning before birth, also caused a reduction in cortical lipid.

It is concluded that the definitive adrenal cortex at birth is responsive to disease and injury. The relationship of this to Selye's stress syndrome is discussed.

We should like to thank Professor A. C. P. Campbell for reviewing the manuscript and Mr. P. Stuart for the photomicrographs and assistance with the charts.

\section{Referenctes}

Bergener, G. E. and Deane, H. W. (1948). Endocrinology, 43, 240.

Bongiovanni, A. M. (1951). Amer. J. med. Sci., 222, 710

Burne, J. C. and Langley, F. A. (1955). In preparation. Greep, R. O. and Deane, H. W. (1949). Amn. N.Y. Acad. Sci., 50. 596.

Gruenwaid, P. (1951). Amer. J. Path., 27, 722.

Heller, H. (1954). É. neionatales, 3, 31.

Jaike, J. W., Wong, A. S. H. and Engle, E. T. (1951). J. clin. Endocr. $11,186$.

Sarason E I (1943) Arch intern Med 71, 702.

Selye, H. (1936a). Brit. J. exp. Path. 17, 234

(1936b). Nature, Lond., 133, 32

and Stone, H. (1950). On the Experimental Morphology of the Adrenal Cortex. (Amer. Lect. Ser. no. 74.) Springfield, Illinois.

Stoner, H. B., Whiteley, H. J. and Emery, J. L. (1953). J. Path. Bact., 66, 174.

Wilson, J. L., Reardon, H. S. and Murayama, M. (1948). Pediatrics,

1, 581. 